\title{
Two Late Recurrences of Conjunctival Melanoma
}

\author{
Niels J. Brouwer ${ }^{a}$ Stijn W. Genders ${ }^{a} \quad$ Marina Marinkovic ${ }^{a}$ \\ Sjoerd G. van Duinen ${ }^{b}$ Martine J. Jager ${ }^{a} \quad$ Gré P.M. Luyten ${ }^{a}$ \\ ${ }^{a}$ Department of Ophthalmology, Leiden University Medical Center, Leiden, The Netherlands; ${ }^{b}$ Department of \\ Pathology, Leiden University Medical Center, Leiden, The Netherlands
}

\section{Established Facts}

- Conjunctival melanoma $(\mathrm{CoM})$ is a rare ocular tumor with a high recurrence rate. It is often treated with local excision and adjuvant therapy.

- Orbital exenteration is a last-resort therapy, with either the intention to be curative or symptomatic.

\section{Novel Insights}

- CoM may give rise to very late recurrences (after 20 years), as well as recurrences after orbital exenteration.

- Long-term awareness - for both patients and doctors - is needed, even after extensive surgical treatment.

\section{Keywords}

Conjunctival melanoma $\cdot$ Treatment $\cdot$ Orbital exenteration

\begin{abstract}
Purpose: To report a patient who developed two late recurrences of conjunctival melanoma (CoM), of which one occurred after orbital exenteration. Methods: We describe the case of a patient based on clinical and histopathological examination. Results: A 52-year-old patient was treated with local excision and cryotherapy for a CoM with primary acquired melanosis (PAM) near the limbus of the right eye. Twenty-one years later, a recurrence developed in the superior fornix of the same eye in an area with widespread PAM;
\end{abstract}

\begin{tabular}{ll}
\hline KARGER & $\begin{array}{l}\text { ( ) 2018 The Author(s) } \\
\text { Published by S. Karger AG, Basel }\end{array}$ \\
E-Mail karger@karger.com & This article is licensed under the Creative Commons Attribution- \\
www.karger.com/oop & $\begin{array}{l}\text { NonCommercial-NoDerivatives 4.0 International License (CC BY- } \\
\text { NC-ND) (http://www.karger.com/Services/OpenAccessLicense). } \\
\text { Usage and distribution for commercial purposes as well as any dis- } \\
\text { tribution of modified material requires written permission. }\end{array}$
\end{tabular}

an orbital exenteration was performed. After another 4 years, a painful nodule developed subcutaneously at the inferior margin of the right orbital socket. Pathology showed a recurrence of CoM with a BRAF V600K mutation, similar to both of the previous lesions (of 25 and 4 years earlier). The nodule was excised without additional therapy. No recurrences or metastases have been observed in the next 2.5 years. The proposed mechanism for the recurrence after surgery could be via dormant tumor cells that have spread prior to the procedure or via residual intraepithelial malignant melanocytes. Conclusion: Very late recurrences of CoM are rare but may occur. Our case illustrates the need for long-term awareness of doctors and patients, even after extensive surgical procedures such as orbital exenteration. (2018 The Author(s) 


\section{Introduction}

Conjunctival melanoma (CoM) is an aggressive ocular disease with an incidence of up to 0.8 per million in adult Caucasians [1]. Treatment of limited disease involves most often local excision with adjuvant therapy, but more extensive procedures may be required in advanced cases. As a last resort, orbital exenteration can be performed. The aim of an orbital exenteration can be either curative, by removing all potentially affected tissues in the orbit, or symptomatic, if the patient experiences discomfort that cannot be resolved otherwise. The risk for local recurrence or metastasis of CoM is high, commonly developing within the first 5-10 years after presentation of the primary lesion [2]. We present a rare case of a patient who developed a very late recurrence of $\mathrm{CoM}$ and another late recurrence after orbital exenteration, stressing the need for adequate long-term follow-up.

\section{Case Report}

A 52-year-old female was diagnosed in 1990 with a CoM on the temporal limbus of the right eye, approximately 4 clock hours in size, with a component of primary acquired melanosis (PAM) (no photograph available). This constituted a cT1, N0, M0 tumor [3], which was treated with local excision and cryotherapy. The melanoma was removed with tumor-free margins (Fig. 1). During the first 10 years of follow-up at our oncology center, no local recurrence or metastasis was detected. In 2001, the patient returned to her local ophthalmologist.

In 2011, 21years after treatment for the primary lesion, the patient returned to our center with a nodular lesion in the superior fornix of the right eye, suspicious for recurrence of the CoM (Fig. 2). Earlier, no abnormalities had been noticed by the patient. A CT scan showed a preseptal lesion, and biopsy proved it to be a CoM. A total orbital exenteration (with removal of the globe, conjunctiva, and eyelids) was performed, and histology of the specimen showed radical excision of the melanoma with widespread PAM (Fig. 1).

Four years later, the now 78-year-old woman presented with a painful subcutaneous nodule on the inferior margin of the right orbit (Fig. 3). MRI showed a hypointense lesion measuring 6 by $4 \mathrm{~mm}$, anterior to the maxillary sinus (Fig. 4). The nodule was excised and proved to be a CoM, with histological similarities to the

Fig. 1. a Histology of the primary CoM in 1990 demonstrated a mixed cell type with both spindle cells and epithelioid cells (H\&E stain, original magnification $40 \times$ ). b Histology of the recurrence in 2011 demonstrated a similar mixed cell type, with mitoses, no ulceration, and no vessel invasion (H\&E stain, original magnification $40 \times$ ). c The subcutaneous nodule in 2015 demonstrated similarities to the lesion from 2011 in cell type, cell size, and cellular configuration (H\&E stain, original magnification $40 \times$ ).

Two Late Recurrences of Conjunctival Melanoma
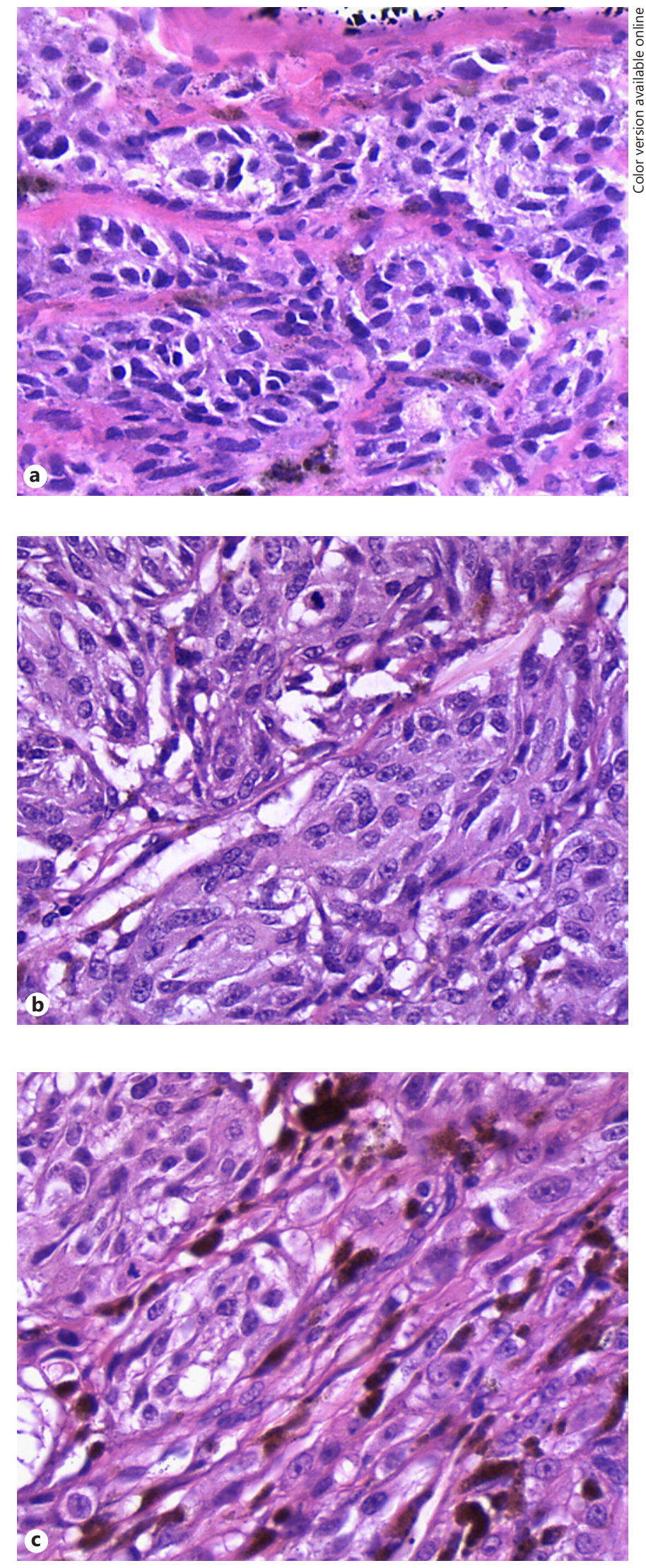

Ocul Oncol Pathol 2019;5:262-266 


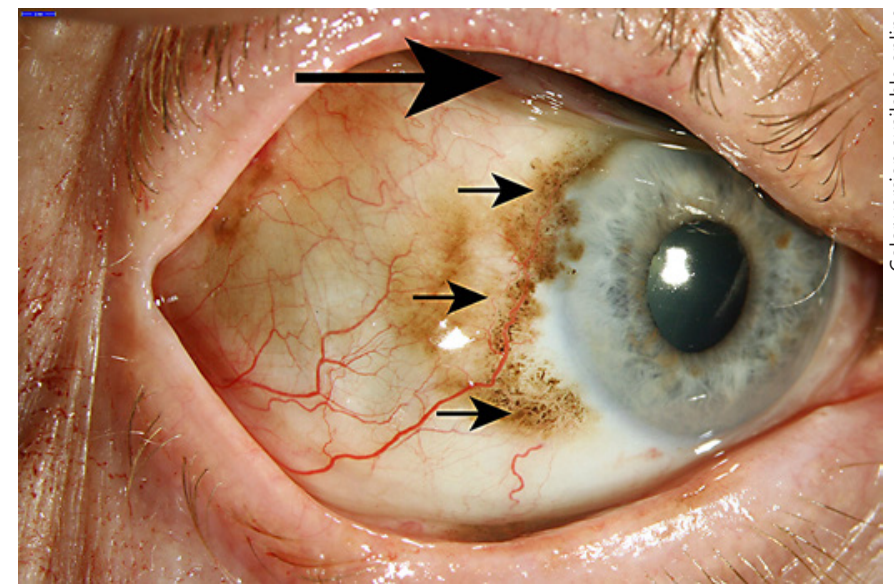

Fig. 2. Slit-lamp photography of the right eye (2011). Widespread melanosis is located on the ocular surface (small arrows), and a large nodule is located in the superior fornix (large arrow).

lesion of 2011 in cell type and configuration (Fig. 1). A mutation in the BRAF gene (p.Val600Lys; V600K) but not in NRAS or KIT was identified in the newest lesion. Additional tests on the tissue of the orbital exenteration and the first lesion from 1990 demonstrated the same BRAF V600K mutation and a similar absence of mutations in NRAS or KIT in both samples. Presurgery screening for metastatic disease by CT of the chest and abdomen revealed multiple lesions in both lungs: a biopsy showed these to be metastases of a newly detected colon carcinoma. For this malignancy, the patient was treated with capecitabine chemotherapy and surgical resection of the sigmoid. The patient did not receive further treatment for the recurrent melanoma, as at that time, excision was regarded as appropriate treatment. A total of 2.5 years after removal of the orbital nodule, the 80 -year-old patient is doing fine regarding her ophthalmic situation, with no other recurrences or metastases. An ultrasound of the neck is performed every 6 months, and this has showed no abnormalities in the cervical lymph nodes so far. The lung lesions from the colon carcinoma have shown only minor progression without need for further treatment.

\section{Discussion}

Local recurrence of CoM is rather common, with an overall 5-year recurrence rate of $36-61 \%[2,4]$. Very late recurrences (after 20 years) are rare, being reported once in a long-term follow-up study of 85 patients [4], once in 194 patients [2], and once in 256 patients [5]. The mean follow-up time of these studies was 13.8 years (with 12 patients followed for longer than 20 years), 9.2 years (with 7 patients followed for longer than 20 years), and 9.0 years (with no reported numbers for 20 years of follow-up), respectively. The development of a late recurrence after or-

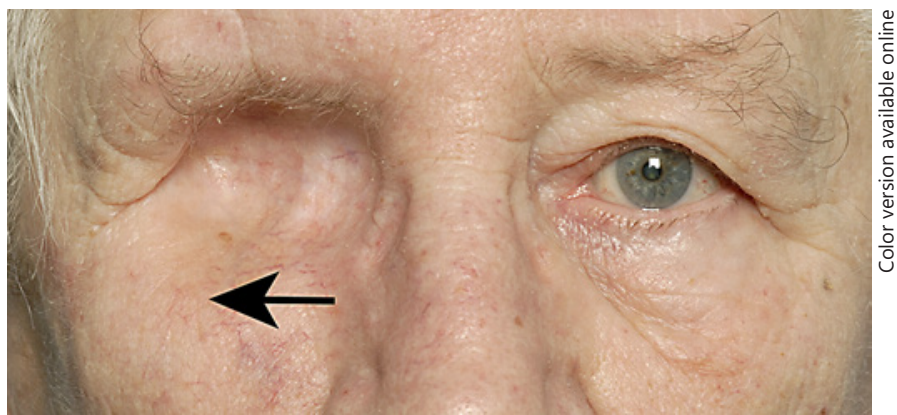

Fig. 3. En face photography of the orbital socket, 1 year before development of the lesion (2014). The lesion was located at the inferior border of the orbital rim (arrow).

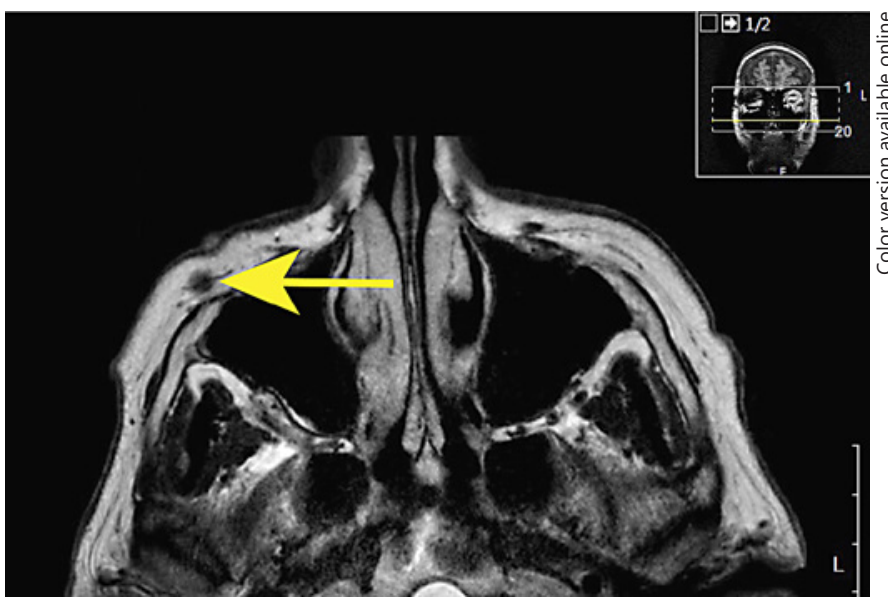

Fig. 4. Magnetic resonance imaging (2015) reveals a hypointense nodule at the inferior border of the orbital rim on a T2-weighed scan (arrow).

bital exenteration is also most unusual. In our case, the patient developed a recurrence 4 years after this procedure. To our knowledge, this kind of recurrence has only been reported once before in a patient who had undergone orbital exenteration 21 years before [6].

The primary conjunctival tumor, the first recurrence, and the subcutaneous nodule in our patient all contained the same mutation in the BRAF gene (V600K). While a $B R A F$ mutation has been reported in $29-50 \%$ of all CoM, the $\mathrm{V} 600 \mathrm{~K}$ mutation is a rare type found in approximate- 
ly $20 \%$ of $B R A F$-mutated CoM, in contrast to the $B R A F$ V600E mutation that makes up nearly all other $80 \%$ [7]. This finding adds to the likelihood that the lesions are related and that both the first lesion and the subcutaneous nodule should be considered a recurrence of CoM. This is no proof, however, since a small study by Larsen et al. [8] (including 8 cases) showed that BRAF mutations can be both present and absent in paired lesions of PAM and melanoma, implying that it may be impossible to distinguish whether the recurrence developed from dormant melanoma cells or from residual PAM. Clinically, this is not relevant as it does not alter the treatment strategy.

Late development of CoM recurrences may be in line with the theory of metastatic dormancy. This has been described in uveal melanoma and to some extent in cutaneous melanoma [9]. It has been hypothesized that environmental factors may induce a senescent state of melanoma cells, allowing for long periods of disease-free survival. It is thought that the immune system plays an important role in the detection of tumor cells. Genetic factors may contribute as well, although the effect of BRAF is unclear. Relevance of metastatic dormancy for CoM is unknown, but an observation as ours implies that it might play a role in some cases.

There are two possible mechanisms for the development of the recurrence after orbital exenteration in our patient. Melanoma cells may have spread in advance of or during the orbital exenteration and subsequently remained dormant for several years. Alternatively, a component of intraepithelial (premalignant) melanocytes might have been left in the orbital socket, later developing into a second primary CoM. Though PAM was widespread in the exenteration specimen, all surgical margins were free, suggesting that the first mechanism is the most likely in our case.

A third explanation for the development of melanoma that we considered is that the lesion is a primary cutaneous melanoma or a secondary lesion of another (nonconjunctival) melanoma [10]. Histologically, there was no relation between the subcutaneous nodule and the cutaneous melanocytes in our patient, indicating that a primary cutaneous origin is very unlikely. As the patient had no other cutaneous or ocular lesions that were suspect for melanoma, a second skin lesion or CoM with local metastatic spreading is unlikely as well. Detection of a (secondary) cutaneous origin could be very relevant, as new treatments with targeted therapy (e.g., BRAF-inhibitors) have become available with potential benefit for selected patients [11]. Various cases have been reported of ocular presentation of disseminated cutaneous mela-

Two Late Recurrences of Conjunctival Melanoma noma, which were successfully treated with these agents [12].

We regard the orbital lesion as a local recurrence of CoM and not as metastatic disease as no other (systemic) lesions were detected, and there are plausible mechanisms for the recurrence to occur. However, this might be a matter of terminology as one might state that a successful orbital exenteration removes all the periocular tissues required for a local recurrence. In contrast to our case of local recurrence, distant metastases of CoM after orbital exenteration have been reported more often [13], with a $35 \%$ rate in a series with 51 months of mean follow-up [14]. However, exact numbers are scarce, possibly because many patients are lost to follow-up after the procedure, as it is not uncommon for patients to return to their local doctor once the orbital exenteration has been performed.

The orbital CoM recurrence in our patient was excised with clear, tumor-free margins. As the patient was diagnosed shortly after this excision with a disseminated colon carcinoma (T3N0M1a, stage IVa) for which a palliative treatment was started, no adjuvant therapy for the CoM lesion was given. Nevertheless, this could be up for discussion as a CoM recurrence might occur again via the mechanisms we proposed earlier, through possibly dormant melanoma cells or residual PAM. Although the patient was treated with capecitabine chemotherapy for her colon carcinoma, this will be of limited relevance as capecitabine (or another form of 5-FU) is not indicated for the treatment of CoM $[15,16]$. Regarding the first episode of CoM with accompanying histologic PAM in our patient, we would currently advise to apply mitomycin $\mathrm{C}$ drops after excision to reduce the recurrence risk [17].

In conclusion, our case shows that very late recurrences of CoM may occur, and that an orbital exenteration should not be regarded as the 'final solution' of CoM treatment. One should be aware of the potential occurrence of either new melanoma or recurrences. Patients with CoM or PAM should preferably be followed in a tertiary reference center. Patients should be instructed to immediately report any changes, and whenever there is even the smallest suspicion of an abnormality, clinicians should not hesitate to perform a MRI of the orbital region.

\section{Statement of Ethics}

The patient gave written informed consent for the publication of this paper. 


\section{Disclosure Statement}

The authors have no financial interests or conflicts of interest to disclose.

\section{Funding Sources}

N.J.B. is the recipient of a $\mathrm{MD} / \mathrm{PhD}$ program grant from the Leiden University Medical Center. The funder had no role in the design or execution of the study.

\section{References}

1 Tuomaala S, Eskelin S, Tarkkanen A, Kivelä T. Population-based assessment of clinical characteristics predicting outcome of conjunctival melanoma in whites. Invest Ophthalmol Vis Sci. 2002 Nov;43(11):3399-408.

2 Missotten GS, Keijser S, De Keizer RJ, De Wolff-Rouendaal D. Conjunctival melanoma in the Netherlands: a nationwide study. Invest Ophthalmol Vis Sci. 2005 Jan;46(1):75-82.

3 Coupland SE, Barnhill RL, Conway M, Damato B, Esmaeli B, Albert DM. Conjunctival melanoma. In: Amin MB, Edge S, Green F, editors: AJCC Canger Staging Manual. 8th ed. New York, Springer; 2017. p. 795-803.

4 Werschnik C, Lommatzsch PK. Long-term follow-up of patients with conjunctival melanoma. Am J Clin Oncol. 2002 Jun;25(3):24855.

5 Paridaens AD, Minassian DC, McCartney AC, Hungerford JL. Prognostic factors in primary malignant melanoma of the conjunctiva: a clinicopathological study of 256 cases. $\mathrm{Br}$ J Ophthalmol. 1994 Apr;78(4):252-9.

6 Paridaens AD, McCartney AC, Lavelle RJ, Hungerford JL. Nasal and orbital recurrence of conjunctival melanoma 21 years after exenteration. Br J Ophthalmol. 1992 Jun;76(6): $369-71$.
7 Mor JM, Heindl LM. Systemic BRAF/MEK Inhibitors as a Potential Treatment Option in Metastatic Conjunctival Melanoma. Ocul Oncol Pathol. 2017 Jul;3(2):133-41.

8 Larsen AC, Dahl C, Dahmcke CM, LadeKeller J, Siersma VD, Toft PB, et al. BRAF mutations in conjunctival melanoma: investigation of incidence, clinicopathological features, prognosis and paired premalignant lesions. Acta Ophthalmol. 2016 Aug;94(5): 463-70.

9 Ossowski L, Aguirre-Ghiso JA. Dormancy of metastatic melanoma. Pigment Cell Melanoma Res. 2010 Feb;23(1):41-56.

10 Rose AM, Cowen S, Jayasena CN, Verity DH, Rose GE. Presentation, treatment, and prognosis of secondary melanoma within the orbit. Front Oncol. 2017 Jun; 7:125.

11 Michielin O, Hoeller C. Gaining momentum: new options and opportunities for the treatment of advanced melanoma. Cancer Treat Rev. 2015 Sep;41(8):660-70.
12 Brouwer NJ, Marinkovic M, Jochems A, Kapiteijn EW, van Duinen SG, Haeseker BI, et al. Conjunctival metastasis of a cutaneous melanoma. Ocul Oncol Pathol. 2018 Sep;4(2): $107-11$.

13 Paridaens AD, McCartney AC, Minassian DC, Hungerford JL. Orbital exenteration in 95 cases of primary conjunctival malignant melanoma. Br J Ophthalmol. 1994 Jul;78(7): 520-8.

14 Shields JA, Shields CL, Gündüz K, Cater J. Clinical features predictive of orbital exenteration for conjunctival melanoma. Ophthal Plast Reconstr Surg. 2000 May;16(3):173-8.

15 Vora GK, Demirci H, Marr B, Mruthyunjaya $\mathrm{P}$. Advances in the management of conjunctival melanoma. Surv Ophthalmol. 2017;JanFeb;62(1):26-42.

16 FDA [internet]: Capecitabine [cited March 8, 2018]. Available from: https://www.accessdata.fda.gov/drugsatfda_docs/label/2005/ 020896s016lbl.pdf.

17 Brouwer NJ, Marinkovic M, van Duinen SG, Bleeker JC, Jager MJ, Luyten GP. Treatment of conjunctival melanoma in a Dutch referral centre. Br J Ophthalmol. 2018 Sep;102(9): 1277-82. 